\title{
Lifestyle and Dietary Behaviors among Saudi Preschool Children Attending Primary Health Care Centers, Eastern Saudi Arabia
}

\author{
Magdy A. Darwish, ${ }^{1}$ Ghadeer Al-Saif, ${ }^{2}$ Suha Albahrani, ${ }^{3}$ and Amr A. Sabra ${ }^{1}$ \\ ${ }^{1}$ Department of Family and Community Medicine, University of Dammam, Saudi Arabia \\ ${ }^{2}$ Qatif Primary Health Care, Ministry of Health, Eastern Province, Saudi Arabia \\ ${ }^{3}$ Dammam Primary Health Care, Ministry of Health, Eastern Province, Saudi Arabia
}

Correspondence should be addressed to Magdy A. Darwish; magdar9123@yahoo.com

Received 24 April 2014; Revised 16 June 2014; Accepted 17 June 2014; Published 10 July 2014

Academic Editor: Samuel Y. S. Wong

Copyright ( 2014 Magdy A. Darwish et al. This is an open access article distributed under the Creative Commons Attribution License, which permits unrestricted use, distribution, and reproduction in any medium, provided the original work is properly cited.

\begin{abstract}
Objective. To study life styles and dietary behaviors among Saudi preschool children (1-5 years) attending primary health care centers (PHCCs) in Dammam and Qatif areas, eastern province, Saudi Arabia. Material and Methods. Cross-sectional study. Data were collected using structured, interviewer-filled questionnaire. Children and their mothers were encountered during their wellbaby clinic visits. A total number of 300 preschool children and their mothers were interviewed during study period. Results. Unsatisfactory areas include smoking fathers (32\%), smoking in front of children (11.3\%), overweight and obesity among mothers (60.3\%), noncompliance using seat belts for both parents (56.3\%) and children (68\%), children watching television (T.V) more than 2 hours (50\%), adherence to exclusive breast feeding (only 20.7\%), and late solid food introduction (65.3\%). Frequent intake of unhealthy food items was $26 \%, 25 \%$, and $24 \%$ for pizza, burger, and soft drinks. Unfortunately frequent intake of the following unhealthy food items was high: biscuits, deserts/chocolates, and chips which was 78\%, 67\%, and 72\%, respectively. Conclusion. This study provides benchmark about the current situation. It provides health care workers and decision makers with important information that may help to improve health services.
\end{abstract}

\section{Introduction}

Recent research has begun to focus on effects of family and social influences on children's lifestyle and eating patterns [1]. Key components of pediatric lifestyle include starting with exclusive breast feeding, optimal nutrition, maintaining appropriate weight, moderate physical activity, optimum sleep duration, and avoidance of long hours of watching television (TV) [2-4]. Cardiovascular risk factors start in early childhood with fatty streaks evident in the arteries of children [4]. Recently, levels of blood cholesterol and triglycerides have been found to be increasing in children while the high density lipoproteins decreased [4]. Moreover Research has demonstrated that both the physical and social environment strongly affect the eating patterns of children [1]. Social environment, including various socioeconomic and sociocultural factors, influence the types of foods that children eat [1]. Parents actually have potential and powerful role in behavioral change strategies which aim to improve the lifestyle behaviors of young children [2]. Parental obesity, low parental educational level, low total family income, long hours of TV watching, absence of breastfeeding, and physical inactivity were significantly associated with childhood overweight/obesity [1]. Low maternal educational level and allowing children to watch TV more than 2 hours were also associated with unhealthy snaky pattern [3]. Overeating-type eating style and sedentary activities are observed frequently in the children from obese/overweight families [5]. This is associated with the fact that these children had a higher preference for fatty foods with a lower liking for vegetables [5]. The mother's work status played a significant role in the early termination of breastfeeding [6]. Early return to work and lack of maternity leave contribute to early cessation of breastfeeding or lack of exclusive breastfeeding [4]. Long hours of maternal employment, rather than lack of money, may impede children's access to healthy foods and physical 
activity but there was no evidence for that association with paternal work [7]. Family income often affects accessibility to healthy food that is why the lower socioeconomic status acts as a barrier to the fruit and vegetables intake and makes the intake of fat higher compared to children in relatively higher socioeconomic groups [1]. However, to fulfill this role, parents need to have the necessary knowledge and motivation to assimilate dietary guidelines [2]. Some day care centers play an important role in the development of children's eating habits by focusing on issues such as providing and making healthful food choices like fruit and vegetables [2]. Playing is very important for child development because it contributes to the cognitive, physical, social, and emotional well-being and should be included along with academic and socialenrichment opportunities [8]. In addition, sleep duration is important for children. An inverse association was observed between sleep duration and the risk of developing childhood overweight/obesity [2]. Promoting healthier eating patterns among children requires a multifaceted approach targeting children, parents, families, and schools. Interventions aimed at improving children's nutrition need first to address variety of social and physical factors that could influence children's eating patterns. Clearly, this area is rich and needs researches to address multiple influences on children's eating patterns and life style.

\section{Methodology}

This cross-sectional study was conducted in PHCCs in Qatif and Dammam areas, eastern region, Saudi Arabia. Study population included Saudi preschool children (1-5 year old) attending chosen PHCCs and their mothers/caregivers. Systemic random sampling technique was used by choosing every second PHCC from lists of PHCCs provided by ministry of health in both Dammam and Qatif areas. A total of 13 centers out of the 27 centers in Qatif and 11 centers out of the 22 centers in Dammam were chosen where children and their caregivers were encountered during their well-baby clinic visits. All preschool children and their mothers attending the chosen centers were interviewed on days of study visit. A total number of 326 preschool children and their mothers were interviewed during study period.

Data were collected using structured, interviewer-filled questionnaire which has been designed by the researchers after reviewing the recent literature and similar questionnaires and based on the objectives of the study putting in consideration sociocultural backgrounds. The questionnaire was divided into four parts: First part included sociodemographic data of the care givers like age, sex, marital status, occupation, and so forth. Second part included questions to assess practice of healthy styles among parents for example smoking, use of seat belt ... and so forth. Third part included child socio-demographic data and child lifestyles, for example, age, sex weight, height, rank, siblings, attending nursery, TV watching, physical activity, sleeping pattern, breast feeding and weaning, and so forth. Fourth part included questions about dietary behaviors of children, for example, number of meals, number of snacks, and so forth. Consumption of different types of commonly available healthy and unhealthy food items (19 item) was evaluated using simplified Arabic frequency questionnaire which has high internal consistency (Cronbach's alpha scores of $>0.74$ ).

A pilot study was conducted on 20 patients-different from the target group-to check understanding and applicability of the questionnaire. Based on the results, some linguistic modifications of questions were made to avoid confusion about questions and make easier understanding and interpretation by participants. Questionnaire was then reviewed by researchers, two of them have Saudi Arabian slang: one from Qatif and the other from Dammam, before and after pilot study for necessary linguistic modifications of some confusing words. Questionnaires were reviewed for completeness and invalid questionnaires were excluded giving a total of 300 valid questionnaires.

Questionnaire was validated after modification. Questionnaire was reviewed by 2 faculties, revised questionnaires were compared and necessary modifications were made before finally approved by the reviewers.

The participants were approached in well baby clinics of chosen primary health care centers. They were met and explained purpose of the study, reassured that questionnaires are anonymous, and informed that collected data will kept confidential and used only for study purpose. The questionnaire was explained to them and all their questions were answered before obtaining their informed consent.

The data were coded, entered, and analyzed in a personal computer using statistical package for social sciences (SPSS) software version 16. Data were presented using descriptive statistics in form of frequencies and percentages for qualitative variables and mean and standard deviation (SD) for quantitative variables. Chi-square test and/or logistic regression analysis were used as appropriate to determine association.

The study was approved by ethical committee of Postgraduate Saudi Board Program, Eastern Province. All necessary approvals from ministry of health including ethical approval were obtained.

\section{Results}

A total of 300 valid questionnaires were obtained representing 300 preschool children and their mother's responses. The mean age for study population mothers in years was $31.2 \pm 5.6$ SD. All care givers in this study were children's mothers. Nearly half of the mothers $(47.7 \%)$ were in age range 30 to 40 years, Most of the sample was married (98.3\%) and $71.3 \%$ of them have very good relationships with the fathers. Educational level of the mothers and fathers in this study was university graduation or above in $50 \%$ and $48.3 \%$, respectively, and more than half of the mothers (52.7\%) were housewives (Table 1).

Some life style characters of parents of study group including smoking habits, use of seat belts, and body mass index of study mothers are illustrated in Table 2 while Table 3 shows the Sociodemographic characteristics and health behaviors of the children participating in the study 
TABLE 1: Sociodemographic data of the parents of the children participating in the study.

\begin{tabular}{|c|c|}
\hline \multirow{2}{*}{ Sociodemographic characteristic } & Total $(n=300)$ \\
\hline & No $\quad \%$ \\
\hline
\end{tabular}

Age of the mother in years

(i) $<20$

(ii) $20-<30$

$3 \quad 1.0$

(iii) $30-<40$

$127 \quad 42.3$

(iv) $\geq 40$

$143 \quad 47.7$

$27 \quad 9.0$

Mean age in years $\pm \mathrm{SD}=31.2 \pm 5.6$

Marital status of the mother

(i) Married with father

(ii) Divorced

(iii) Widow

$\begin{array}{cc}295 & 98.4 \\ 4 & 1.3 \\ 1 & 0.3\end{array}$

Educational level of the mother

(i) Illiterate/Read and write

(ii) Primary school

(iii) Intermediate

(iv) High or diploma

(v) University or more

Educational level of the father

(i) Illiterate/Read and write

(ii) Primary school

(iii) Intermediate

(iv) High or diploma

(v) University or more

Total family income in Saudi Riyals (SR)
(i) $<2000$
(ii) 2000-4999

$54 \quad 18.0$
(iii) 5000-9999
$104 \quad 34.7$
(iv) 10000-14999
$59 \quad 19.7$
(v) 15000 or more

$\begin{array}{ll}73 & 24.3\end{array}$

Relationship between parents (mother statement)

(i) Very good

214

(ii) Good

5.9

71.3

(iii) Minor problems

20

19.7

(iv) Major problems

(v) Separated

$3 \quad 1.0$

$4 \quad 1.3$

Family type

(i) Nuclear family

(ii) Extended family

$213 \quad 71.0$

$87 \quad 29.0$

Mother work

(i) Housewife

$158 \quad 52.7$

(ii) Employed

142

father work

(i) Not working

(ii) Manual worker

$14 \quad 4.7$

(iii) Professional

$30 \quad 10.0$

$256 \quad 85.3$

including age, sex, birth order, number of siblings, and child morbidity. Table 4 illustrates health behaviors of the children including playing patterns, TV watching, modes of breast feeding and weaning, nursery/kindergarten attendance, and
TABLE 2: Life style of parents of study group children.

\begin{tabular}{lcc}
\hline Life style of the parents & \multicolumn{2}{c}{ Total $(n=300)$} \\
\hline Smoking & No & \\
$\quad$ (i) Smoking father & 96 & 32.0 \\
$\quad$ (ii) Smoking mother & 4 & 1.3 \\
$\quad$ (iii) Smoking in front children & 34 & 11.3 \\
Fastening seat belt & & \\
$\quad$ (i) Parents fastening seatbelt & 131 & 43.7 \\
$\quad$ (ii) Children fastening seatbelt & 96 & 32.0 \\
BMI of the mother & & \\
$\quad$ (i) Underweight $(<18.5)$ & 9 & 3.0 \\
(ii) Normal (18.5-<25) & 110 & 36.7 \\
(iii) Overweight $(25-<30)$ & 96 & 32.0 \\
(iv) Obese class $1(30-<35)$ & 53 & 17.6 \\
(v) Obese class 2 $(35-<40)$ & 24 & 8.0 \\
$\quad$ (vi) Morbid obese $(40$ or more) & 8 & 2.7 \\
\hline
\end{tabular}

meal and snacking patterns. Distribution of studied children according to their nutritional status showed that all anthropometric measurements lie within normal range for study population children. Weight and height were measured and then weight for age, height for age, and weight for height were calculated for all children participating in this study using standard age suitable charts. All charts used were latest Saudi growth charts used by $\mathrm{MOH}$ (Table 5). Factors related to consumption of healthy food items among study population preschool children are shown in Table 6 . Consuming more vegetables was significantly related to number of meals per day $(P=0.00)$, while frequency of fruit consumption was more in children whom mothers were housewives $(P=0.00)$, children living in nuclear family $(P=$ $0.03)$, and children eating more snacks $(P=0.00)$. Legumes consumption was more among those living in Dammam $(P=0.00)$ and in children consuming more meals $(P=$ $00.04)$. $60.20 \%$ of children who consume frequent amount of legumes were taking three meals/day. Factors significantly affecting consuming unhealthy food items in preschool study population children are shown in Tables 7 and 8. Children rising in nuclear families were consuming pizza and burger more frequently than children rising in extended families (75.90\% and $81.60 \%$, resp.), while children of families living in Qatif were consuming burger and soft drinks less frequently. Soft drinks consumption was also less frequent in children who eat more meals $(P=0.002)$ and among children not attending and those attending less months in nursery or kindergarten $(P=0.015)$ (Table 7). Children in families with higher total monthly income were consuming more amounts of biscuit $(P=0.049)$. Also children who were not attending nursery or kindergarten where consuming more amount deserts/chocolate $(P=0.04)$. Watching T.V more than 2 hours was associated with more frequent consumption of deserts/chocolate and chips $(P=0.025)$ and $(P=$ $0.006)$, respectively. In addition, chips consumption was more 
TABLE 3: Sociodemographic characteristics of the children participating in the study.

\begin{tabular}{lcc}
\hline $\begin{array}{l}\text { Sociodemographic characteristics of the } \\
\text { children }\end{array}$ & \multicolumn{2}{c}{ Total $(n=300)$} \\
\hline Child age in years & No & \\
$\quad$ (i) 1 year & 43 & 14.3 \\
(ii) 2 years & 75 & 25.0 \\
(iii) 3 years & 52 & 17.3 \\
(iv) 4 years & 50 & 16.7 \\
(v) 5 years & 80 & 26.7
\end{tabular}

Child sex

(i) Male

(ii) Female

Child order

(i) $1 \mathrm{st}$

(ii) $2 \mathrm{nd}$

(iii) $3 \mathrm{rd}$

(iv) 4 th

(v) 5 th or more

Number of siblings

(i) No siblings

(ii) 1 sibling

(iii) 2 siblings

(iv) 3 siblings

(v) 4 siblings or more

Child attending nursery or kindergarten (KG)

(i) Attending

(ii) Not-attending

Number of months attended in nursery or KG/year
(i) 3-5 months
(ii) 6-8 months
(iii) 9-12 months
(iv) Not-attending

111

37.0

23.3

11.7

12.0

16.0

48

Number of hours attended in nursery or KG/day
(i) 3-6 hours
(ii) 7-10 hours
(iii) Not-attending

Number of meals eaten in nursery or KG

$\begin{array}{lcc}\text { (i) } 1 \text { meal } & 57 & 19.0 \\ \text { (ii) } 2 \text { meals } & 27 & 9.0 \\ \text { (iii) } 3 \text { meals } & 2 & 0.7 \\ \text { (iv) Not-attending } & 214 & 71.3\end{array}$

frequent in children of housewife mothers $(P=0.037)$ (Table 8).
TABLE 4: Health behaviors of the children participating in the study.

\begin{tabular}{|c|c|c|}
\hline \multirow{2}{*}{ Health behaviors } & \multicolumn{2}{|c|}{ Total $(n=300)$} \\
\hline & No & $\%$ \\
\hline \multicolumn{3}{|l|}{ TV watching hours/day } \\
\hline (i) $<2$ hours & 150 & 50.0 \\
\hline (ii) $\geq 2$ hours & 150 & 50.0 \\
\hline \multicolumn{3}{|l|}{ Playing hours/day } \\
\hline (i) $<2$ hours & 33 & 11.0 \\
\hline (ii) 2-4 hours & 128 & 42.7 \\
\hline (iii) $\geq 5$ hours & 139 & 46.3 \\
\hline \multicolumn{3}{|l|}{ Breast feeding duration } \\
\hline (i) Never & 32 & 10.7 \\
\hline (ii) $<6$ months & 79 & 26.3 \\
\hline (iii) 6 months $-<1$ year & 60 & 20.0 \\
\hline (iv) 1 year $-<1.5$ year & 39 & 13.0 \\
\hline (v) $1.5-2$ year & 90 & 30.0 \\
\hline \multicolumn{3}{|l|}{ Bottle feeding duration } \\
\hline (i) never & 62 & 20.7 \\
\hline (ii) $<6$ months & 76 & 25.3 \\
\hline (iii) 6 months $-<1$ year & 36 & 12.0 \\
\hline (iv) 1 year-<1.5 year & 33 & 11.0 \\
\hline (v) $1.5-2$ year & 93 & 31.0 \\
\hline \multicolumn{3}{|c|}{ Solid food introduction in age } \\
\hline (i) $<6$ months & 104 & 34.7 \\
\hline (ii) 6 months or more & 196 & 65.3 \\
\hline \multicolumn{3}{|l|}{ Number of meals/day } \\
\hline (i) 1 meal & 12 & 4.0 \\
\hline (ii) 2 meals & 87 & 29.0 \\
\hline (iii) 3 meals & 190 & 63.3 \\
\hline (iv) 4 meals & 11 & 3.7 \\
\hline \multicolumn{3}{|l|}{ Number of snacks/day } \\
\hline (i) 1 snack & 82 & 27.3 \\
\hline (ii) 2 snacks & 154 & 51.4 \\
\hline (iii) 3 snacks & 55 & 18.3 \\
\hline (iv) 4 snacks & 9 & 3.0 \\
\hline
\end{tabular}

\section{Discussion}

Frequency of smoking among fathers was $32 \%$, while $1.3 \%$ of mothers were smokers. $11.3 \%$ of children were passive smokers due to father or mother smoking. These percentages are in the ranges of the national data. Bassiony (2009) in his study showed prevalence of smoking in Saudi males ranges from 13 to $38 \%$ (median $=26.5 \%$ ), while in Saudi females it ranges from 1 to $16 \%$ (median $=9 \%$ ) [9]. A study done in Germany shows that $28.5 \%$ of fathers and $20.7 \%$ of mothers were smokers [10]. Characteristically in our study prevalence of smoking among mothers was low in contrast to smoking among fathers.

Regarding fastening seatbelt, $43.7 \%$ of parents who participated in our study used to fasten seatbelt. A study done in eastern province in Saudi Arabia shows that the usage of seatbelts ranged from 17 to $100 \%$ with a mean of $56.8 \%$ [11]. Another study done in Riyadh showed that $62.4 \%$ of 
TABLE 5: Distribution of studied children according to their nutritional status.

\begin{tabular}{|c|c|c|c|c|c|}
\hline Anthropometric measurement & Nutritional status & No & $\%$ & Minimum & Maximum \\
\hline \multirow{3}{*}{ Weight/age } & Under weight & 0 & 0.00 & \multirow{3}{*}{-1.48} & \multirow{3}{*}{1.58} \\
\hline & Normal & 300 & 100.00 & & \\
\hline & Over weight & 0 & 0.00 & & \\
\hline \multirow{3}{*}{ Height/age } & Stunted & 0 & 0.00 & \multirow{3}{*}{-1.28} & \multirow{3}{*}{1.65} \\
\hline & Normal & 300 & 100.00 & & \\
\hline & Tall & 0 & 0.00 & & \\
\hline \multirow{3}{*}{ Weight/height } & Wasted & 0 & 0.00 & \multirow{3}{*}{1.59} & \multirow{3}{*}{1.23} \\
\hline & Normal & 300 & 100.00 & & \\
\hline & Over weight & 0 & 0.00 & & \\
\hline \multicolumn{3}{|c|}{ Total } & 300 & 100,00 & \\
\hline
\end{tabular}

TABLE 6: Factors significantly affecting consumption of healthy food items (vegetables, fruits, and legumes) in preschool study population children.

\begin{tabular}{|c|c|c|c|c|c|c|c|}
\hline \multicolumn{8}{|c|}{ Vegetables } \\
\hline & \multicolumn{2}{|c|}{ Rare $(n=28)$} & \multicolumn{2}{|c|}{ Infrequent $(n=29)$} & \multicolumn{2}{|c|}{ Frequent $(n=243)$} & \multirow{2}{*}{$\begin{array}{l}\text { Test of significance } \\
(P \text { value })\end{array}$} \\
\hline & No & $\%$ & No & $\%$ & No & $\%$ & \\
\hline \multicolumn{8}{|c|}{ Number of meals/day } \\
\hline (i) 1 meal & 5 & 17.90 & 3 & 10.30 & 4 & 1.60 & \multirow{4}{*}{$\begin{array}{l}X^{2}=32.10 \\
(P=0.00)\end{array}$} \\
\hline (ii) 2 meals & 8 & 28.90 & 15 & 51.70 & 64 & 26.30 & \\
\hline (iii) 3 meals & 15 & 53.60 & 11 & 37.90 & 164 & 67.50 & \\
\hline (iv) 4 meals & 0 & 00.00 & 0 & 00.00 & 11 & 4.50 & \\
\hline \multicolumn{8}{|c|}{ Fruits } \\
\hline & \multicolumn{2}{|c|}{ Rare $(n=20)$} & \multicolumn{2}{|c|}{ Infrequent $(n=22)$} & \multicolumn{2}{|c|}{ Frequent $(n=258)$} & \multirow{2}{*}{$\begin{array}{l}\text { Test of significance } \\
(P \text { value })\end{array}$} \\
\hline & No & $\%$ & No & $\%$ & No & $\%$ & \\
\hline \multicolumn{8}{|l|}{ Mother work } \\
\hline (i) Housewife & 16 & 80.80 & 12 & 54.40 & 130 & 50.40 & \multirow{2}{*}{$\begin{array}{l}X^{2}=6.56 \\
(P=0.038)\end{array}$} \\
\hline (ii) Working & 4 & 20.00 & 10 & 46.60 & 128 & 49.60 & \\
\hline \multicolumn{8}{|l|}{ Type of the family } \\
\hline (i) Nuclear & 9 & 45.00 & 16 & 72.70 & 188 & 72.90 & \multirow{2}{*}{$\begin{array}{l}X^{2}=7.03 \\
(P=0.03)\end{array}$} \\
\hline (ii) Extended & 11 & 55.00 & 6 & 27.30 & 70 & 27.10 & \\
\hline \multicolumn{8}{|c|}{ Number of snack/day } \\
\hline (i) 1 snack & 6 & 30.00 & 15 & 68.20 & 61 & 23.60 & \multirow{4}{*}{$\begin{array}{l}X^{2}=26.90 \\
(P=0.00)\end{array}$} \\
\hline (ii) 2 snacks & 12 & 60.00 & 4 & 18.20 & 138 & 53.50 & \\
\hline (iii) 3 snacks & 2 & 10.00 & 1 & 4.50 & 52 & 20.20 & \\
\hline (iv) 4 snacks & 0 & 00.00 & 2 & 9.10 & 7 & 2.70 & \\
\hline \multicolumn{8}{|c|}{ Legumes } \\
\hline & \multicolumn{2}{|c|}{ Rare $(n=147)$} & \multicolumn{2}{|c|}{ Infrequent $(n=50)$} & \multicolumn{2}{|c|}{ Frequent $(n=103)$} & \multirow{2}{*}{$\begin{array}{l}\text { Test of significance } \\
(P \text { value })\end{array}$} \\
\hline & No & $\%$ & No & $\%$ & No & $\%$ & \\
\hline \multicolumn{8}{|l|}{ City } \\
\hline (i) Qatif & 85 & 57.80 & 19 & 38.00 & 46 & 44.70 & \multirow{2}{*}{$\begin{array}{l}X^{2}=7.65 \\
(P=0.00)\end{array}$} \\
\hline (ii) Dammam & 62 & 42.20 & 31 & 62.00 & 57 & 55.30 & \\
\hline \multicolumn{8}{|l|}{ Number of meals } \\
\hline (i) 1 meal & 9 & 6.10 & 1 & 2.00 & 2 & 1.90 & \multirow{4}{*}{$\begin{array}{l}X^{2}=13.18 \\
(P=00.04)\end{array}$} \\
\hline (ii) 2 meals & 45 & 30.60 & 6 & 12.00 & 36 & 35.00 & \\
\hline (iii) 3 meals & 88 & 59.90 & 40 & 80.00 & 62 & 60.20 & \\
\hline (iv) 4 meals & 5 & 3.40 & 3 & 6.00 & 3 & 2.90 & \\
\hline
\end{tabular}


TABLE 7: Factors significantly affecting consuming unhealthy food items (pizza, burger, and soft drinks) in preschool study population children.

\begin{tabular}{|c|c|c|c|c|c|c|c|}
\hline & & & & & & & \\
\hline & Rar & 148) & Infr & $(n=73)$ & Fre & $n=79)$ & Test of significance \\
\hline & No & $\%$ & No & $\%$ & No & $\%$ & $(P$ value $)$ \\
\hline Type of the family & & & & & & & \\
\hline (i) Nuclear & 92 & 62.20 & 61 & 83.60 & 60 & 75.90 & $X^{2}=12.14$ \\
\hline (ii) Extended & 56 & 37.80 & 12 & 16.40 & 19 & 24.10 & $(P=0.002)$ \\
\hline & & & & & & & \\
\hline & Rar & 177) & Infr & $(n=47)$ & Fre & $n=76)$ & Test of significance \\
\hline & No & $\%$ & No & $\%$ & No & $\%$ & $(P$ value $)$ \\
\hline City & & & & & & & \\
\hline (i) Qatif & 96 & 54.20 & 16 & 34.00 & 38 & 50.00 & $X^{2}=6.05$ \\
\hline (ii) Dammam & 81 & 45.80 & 31 & 66.00 & 38 & 50.00 & $(P=0.048)$ \\
\hline Type of the family & & & & & & & \\
\hline (i) Nuclear & 112 & 63.30 & 39 & 83.00 & 62 & 81.60 & $X^{2}=12.53$ \\
\hline (ii) Extended & 65 & 36.70 & 8 & 17.00 & 14 & 18.40 & $(P=0.002)$ \\
\hline & & & Soft & & & & \\
\hline & Rar & 202) & Infr & $(n=26)$ & Fre & $n=72)$ & Test of significance \\
\hline & No & $\%$ & No & $\%$ & No & $\%$ & $(P$ value $)$ \\
\hline City & & & & & & & \\
\hline (i) Qatif & 108 & 53.5 & 15 & 57.7 & 27 & 37.5 & $X^{2}=6.08$ \\
\hline (ii) Dammam & 94 & 46.5 & 11 & 42.3 & 45 & 62.5 & $(P=0.048)$ \\
\hline Number of meals & & & & & & & \\
\hline (i) 1 meal & 10 & 5.00 & 0 & 0.000 & 2 & 2.80 & \\
\hline (ii) 2 meals & 43 & 21.30 & 9 & 34.60 & 35 & 48.60 & $X^{2}=20.77$ \\
\hline (iii) 3 meals & 141 & 69.80 & 16 & 61.50 & 33 & 45.80 & $(P=0.002)$ \\
\hline (iv) 4 meals & 8 & 4.00 & 1 & 3.80 & 2 & 2.80 & \\
\hline Number of month & & & & & & & \\
\hline (i) 0 & 149 & 73.80 & 15 & 57.70 & 50 & 69.40 & \\
\hline (ii) $3-5$ & 2 & 10.00 & 17 & 65.40 & 0 & 0 & $X^{2}=33.38$ \\
\hline (iii) 6-8 & 28 & 13.90 & 5 & 19.20 & 12 & 16.70 & $(P=0.015)$ \\
\hline (iv) 9-12 & 23 & 11.50 & 4 & 15.30 & 10 & 12.60 & \\
\hline
\end{tabular}

participants were fastening seatbelt [12]. A regional study done in gulf area shows that the median percentage of the seatbelt noncompliance was significantly higher in the Gulf countries $(52 \%)$ compared with the high-income countries $(14.5 \%)(P<0.001)$ [13]. Fastening seat belt among parents was less in our study than national, regional, and international studies. Only $34 \%$ of parents of children in our study were fastening seatbelt compared to only $24 \%$ in Jeddah [14], while a study done in USA shows that $91 \%$ of children were strained in the car [15].

This means that fastening seatbelt awareness and rules in our country is underdeveloped and needs improvement.

About weight in our study, mothers showed that $36.7 \%$ have normal body weight, $32 \%$ were overweight, and $28.1 \%$ were obese which is similar to results of the study of AlNozha done in KSA 2005 that showed overall prevalence of obesity $35.6 \%$ (95\% CI: 34.9-36.3), while severe (gross) obesity was $3.2 \%$ [16]. In Bahrain, approximately $32 \%$ of women were obese (BMI $\geq 30$ ) [17]. Generally speaking there is a significant increase in the incidence of obesity with a prevalence of $2 \%-55 \%$ in adult females and $1 \%-$ $30 \%$ in adult males over the Arabic-speaking countries [18].

In our study population, $50 \%$ of the children watch T.V for less than 2 hours and the remaining 50\% watch for 2 hours or more. The American Academy of Pediatrics (AAP) recommends that children 2 years and older watch $<2$ hours of television per day and that children younger than 2 years watch no television [19]. However, 26\% of US children watched 4 or more hours of television per day and $67 \%$ watched at least 2 hours per day [20]. In our study TV watching was associated with more frequent consumption of unhealthy items (chips and chocolate). Studies have shown unhealthy pattern of diets with TV watching with more unhealthy items and less healthy items intake and less frequent meals [21-23]. 
TABLE 8: Factors significantly affecting consuming unhealthy food items (pizza, burger, and soft drinks) in preschool study population children.

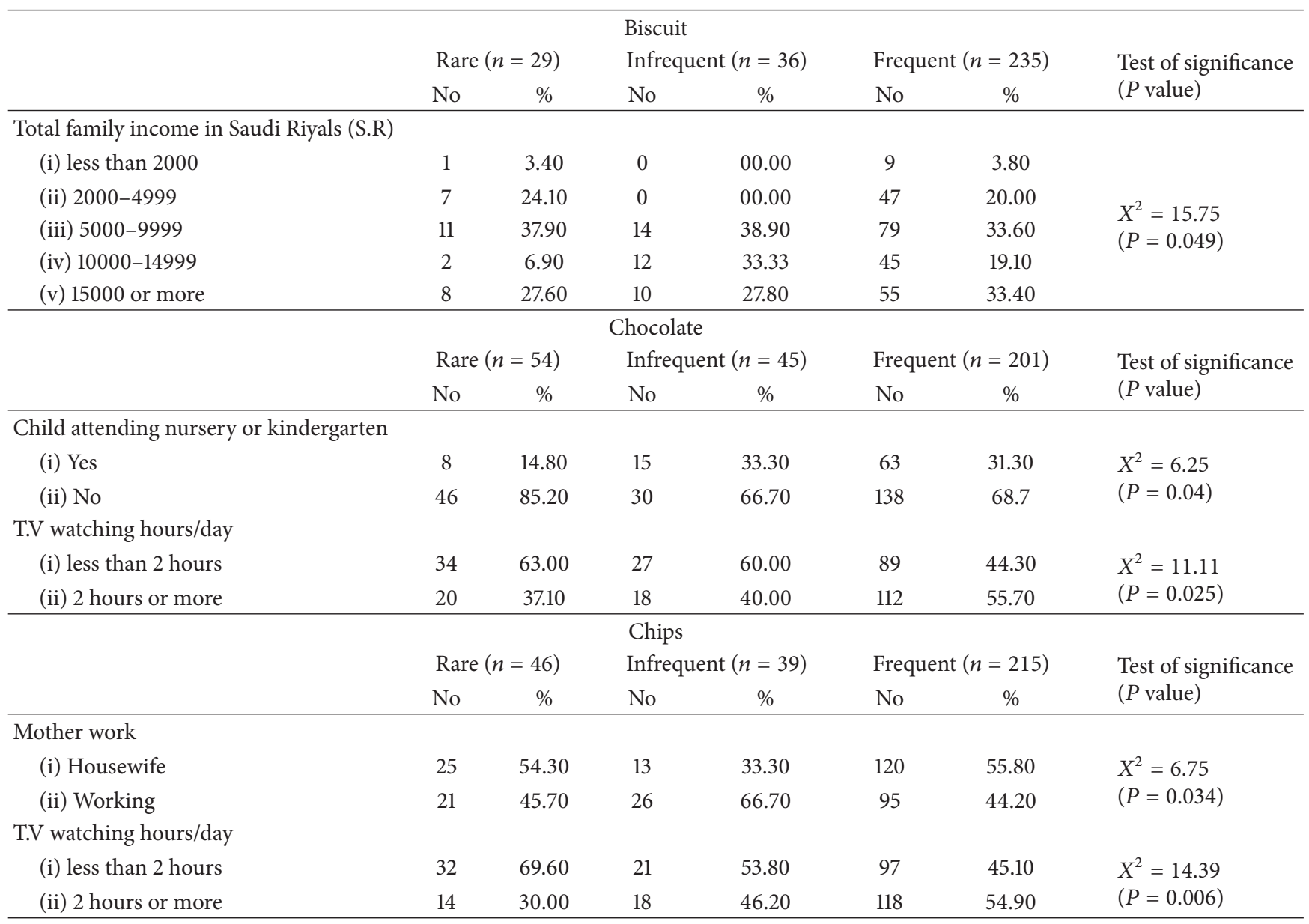

Time spent in playing by most children in our study was satisfactory. Only $11 \%$ of children spend less than 2 hours in playing while $42.7 \%$ spend 2 to 4 hours in playing and $46.3 \%$ spend 5 hours or more in playing. National Association for Sport and Physical Education (NASPE) guidelines recommend for preschool children to (engage in at least 60 minutes-up to several hours-of unstructured physical activity each day and should not be sedentary for more than 60 minutes at a time, except when sleeping) [24].

Although the world health organization (WHO) recommends exclusive breast feeding up to 6 months duration [25], we found in our study that only $20.7 \%$ of the mothers exclusively breastfed their babies, $68.6 \%$ were on mixed feeding, $10.7 \%$ of the mothers never breastfed their babies, and $26.3 \%$ have less than 6 months duration of breast feeding. Prevalence of exclusive breastfeeding was extremely low in our population while partial breastfeeding was the trend for feeding in the first 6 months of life; similar results were concluded from many studies done in Saudi Arabia which was accompanied with rapid decline in lactation duration $[26,27]$.

In this study we found that $65.3 \%$ of children were introduced solid food at age of 6 month or more while $34.7 \%$ of children were introduced before the age of 6 months. This means that still there is misconception about the proper age of introduction of solid food. WHO recommends introduction of solid food around the age of 6 month [28], and recent studies show that late introduction of food was associated with increased risk of allergic sensitization to food $[29,30]$ and inhalant allergens [29].

Regarding frequency of consumption of different food items, consumption of the following healthy items was noticeably rare among study participants: red meat (16\%), white meat (9\%), fish (25\%), beans (49\%), eggs $(11.7 \%)$, and nuts $(49.7 \%)$.

Unfortunately consumption of the following unhealthy items was frequent (that is consumed most of the days) among study participants: pizza (26.4\%), burger (25.3\%), chocolate/desert (67\%), butter-mayonnaise (25\%), soft drinks (24\%), juices (87\%), chips (71.7\%), and biscuits (78.3\%).

In our group study, there was a positive relation between family income and biscuits eating. In 2003 Xiea B showed that increased fast-food consumption was independently associated with higher household incomes [31].

Children living in nuclear families were found to consume more unhealthy items (pizza and burger) than children 
living in extended families. As extended families has members from old generation whom consuming homemade food more as shown in a study done in USA [32].

Children living in Qatif (rural area) were consuming less unhealthy items (burger and soda) than those living in Dammam (urban area). Colić-Barić et al. (2004) showed that Consumption of fast food and soft drinks was more prevalent in urban than rural area [33].

Strangely legumes (healthy food item) intake was lower among children of Qatif area. This can be explained by high prevalence of G6PD deficiency in this area.

Children attending nursery were consuming less deserts/chocolate and drinking more soft drinks in our study. Russell and Worsley (2007) showed that there were no significant associations between attending day care facility and children's food preferences [34].

In our study we found that increasing meal frequency was associated with less frequent soft drinks, more frequent vegetables and legumes and that children who consume more snacks consume more fruit.

Regular meals are associated with improved dietary intake among family members [35]. For example, several large studies have shown that regular family meals are strongly associated with increased consumption of fruits, vegetables, and grains and also linked with lesser consumption of fried or fatty foods and soft drinks or other unhealthy food choices [36-40].

Bellisle (2007) stated that having up to 3 snacks a day can have a positive, rather than a negative, impact on health [41]. The study of Pedersen et al. (2012) showed significant association between irregular breakfast, lunch and evening meal consumption and low frequency of fruit intake and vegetable intake [42]. Lazzeri et al. (2013) showed significant relation between low fruit and vegetable intake and irregular breakfast habits. Similarly, low fruit intake was associated with irregular snack consumption [43].

\section{Conclusion}

Studying life styles, dietary behaviors, and factors that may affect them among preschool children provides benchmark about current situation. It provides health care workers and decision makers with important information that will help to improve health services especially by providing effective, preventive health education and health promotion services to improve situation in this vulnerable sector of the community.

\section{Conflict of Interests}

The authors declare that there is no conflict of interests regarding the publication of this paper.

\section{References}

[1] H. Patrick and T. A. Nicklas, "A review of family and social determinants of children's eating patterns and diet quality," Journal of the American College of Nutrition, vol. 24, no. 2, pp. 83-92, 2005.
[2] J.-P. Chaput, M. Brunet, and A. Tremblay, "Relationship between short sleeping hours and childhood overweight/obesity: results from the "Québec en Forme" project," International Journal of Obesity, vol. 30, no. 7, pp. 1080-1085, 2006.

[3] J. Aranceta, C. Pérez-Rodrigo, L. Ribas, and L. Serra-Majem, "Sociodemographic and lifestyle determinants of food patterns in Spanish children and adolescents: the enKid study," European Journal of Clinical Nutrition, vol. 57, no. 1, pp. S40-S44, 2003.

[4] J. Y. Meek, "Pediatric Lifestyle Medicine," American Journal of Lifestyle Medicine, vol. 6, no. 6, pp. 440-447, 2012.

[5] J. Wardle, C. Guthrie, S. Sanderson, L. Birch, and R. Plomin, "Food and activity preferences in children of lean and obese parents," International Journal of Obesity, vol. 25, no. 7, pp. 971977, 2001.

[6] W. J. Hwang, W. J. Chung, D. R. Kang, and M. H. Suh, "Factors affecting breastfeeding rate and duration," Journal of Preventive Medicine and Public Health, vol. 39, no. 1, pp. 74-80, 2006.

[7] S. S. Hawkins, T. J. Cole, C. Law et al., "Maternal employment and early childhood overweight: findings from the UK Millennium Cohort Study," International Journal of Obesity, vol. 32, no. 1, pp. 30-38, 2008.

[8] K. R. Ginsburg, "The importance of play in promoting healthy child development and maintaining strong parent-child bonds," Pediatrics, vol. 119, no. 1, pp. 182-191, 2007.

[9] M. M. Bassiony, "Smoking in Saudi Arabia," Saudi Medical Journal, vol. 30, no. 7, pp. 876-881, 2009.

[10] G. D. Simonetti, R. Schwertz, M. Klett, G. F. Hoffmann, F. Schaefer, and E. Wühl, "Determinants of blood pressure in preschool children: the role of parental smoking," Circulation, vol. 123, no. 3, pp. 292-298, 2011.

[11] D. A. Al-Dakheel, A. I. Al-Mohimeed, D. S. Shriyan, and M. Sadat-Ali, "Voluntary seatbelt usage. Did we reach there yet?" Neurosciences, vol. 10, no. 1, pp. 114-115, 2005.

[12] I. A. Al-Honazil, M. A. Almazroa, and N. Alhamdan, "Knowledge and behaviour of the medical services department of armed forces employees toward seat belt use, Riyadh," Saudi Epidemiology Bulletin, vol. 15, pp. 21-23, 2007.

[13] A. Abbas, A. Hefny, and F. Abu-Zidan, "Seatbelt compliance and mortality in the Gulf Cooperation Council countries in comparison with other high-income countries," Annals of Saudi Medicine, vol. 31, no. 4, pp. 347-350, 2011.

[14] M. M. Jan, F. H. Hasanain, and A. A. Al-Dabbagh, "Infant and child safety practices of parents," Saudi Medical Journal, vol. 21, no. 12, pp. 1142-1146, 2000.

[15] B. E. Ebel, T. D. Koepsell, E. E. Bennett, and F. P. Rivara, "Too small for a seatbelt: predictors of booster seat use by child passengers," Pediatrics, vol. 111, no. 4, pp. e323-e327, 2003.

[16] M. M. Al-Nozha, Y. Y. Al-Mazrou, M. A. Al-Maatouq et al., "Obesity in Saudi Arabia," Saudi Medical Journal, vol. 26, no. 5, pp. 824-829, 2005.

[17] F. Al-Mahroos and K. Al-Roomi, "Obesity among adult Bahraini population: impact of physical activity and educational level," Annals of Saudi Medicine, vol. 21, no. 3-4, pp. 183$187,2001$.

[18] M. Badran and I. Laher, "Obesity in arabic-speaking countries," Journal of Obesity, vol. 2011, Article ID 686430, 9 pages, 2011.

[19] The American Academy of Pediatrics, 2014, http://www.aap. org/en-us/advocacy-and-policy/aap-health-initiatives/pages/ media-and-children.aspx. 
[20] R. E. Andersen, C. J. Crespo, S. J. Bartlett, L. J. Cheskin, and M. Pratt, "Relationship of physical activity and television watching with body weight and level of fatness among children results from the third national health and nutrition examination survey," Journal of the American Medical Association, vol. 279, no. 12, pp. 938-942, 1998.

[21] J. Utter, R. Scragg, and D. Schaaf, "Associations between television viewing and consumption of commonly advertised foods among New Zealand children and young adolescents," Public Health Nutrition, vol. 9, no. 5, pp. 606-612, 2006.

[22] K. A. Coon, J. Goldberg, B. L. Rogers, and K. L. Tucker, "Relationships between use of television during meals and children's food consumption patterns," Pediatrics, vol. 107, no. 1, p. E7, 2001.

[23] K. J. Campbell and K. D. Hesketh, "Strategies which aim to positively impact on weight, physical activity, diet and sedentary behaviours in children from zero to five years. A systematic review of the literature," Obesity Reviews, vol. 8, no. 4, pp. 327338, 2007.

[24] National Association for Sport and Physical Education, "National guidlines-national guidelines of physical activity," http://www.aahperd.org.

[25] World Health Organization, Exclusive Breastfeeding, http:// www.who.int/nutrition/topics/exclusive_breastfeeding/en/.

[26] S. N. Al-Shehri, M. K. Farag, M. H. Baldo, Y. Y. Al-Mazrou, and K. M. S. Aziz, "Overview on breastfeeding patterns in Saudi Arabia," Journal of Tropical Pediatrics, vol. 41, no. 1, pp. 38-44, 1995.

[27] M. I. El Mouzan, A. A. Al Omar, A. A. Al Salloum, A. S. Al Herbish, and M. M. Qurachi, "Trends in infant nutrition in Saudi Arabia: compliance with WHO recommendations," Annals of Saudi Medicine, vol. 29, no. 1, pp. 20-23, 2009.

[28] World health organization (WHO), Infant and young child feeding, 2014, http://www.who.int/mediacentre/factsheets/fs $342 / \mathrm{en} /$.

[29] B. I. Nwaru, M. Erkkola, S. Ahonen et al., "Age at the introduction of solid foods during the first year and allergic sensitization at age 5 years," Pediatrics, vol. 125, no. 1, pp. 50-59, 2010.

[30] A. Zutavern, I. Brockow, B. Schaaf et al., "Timing of solid food introduction in relation to eczema, asthma, allergic rhinitis, and food and inhalant sensitization at the age of 6 years: results from the prospective birth cohort study LISA," Pediatrics, vol. 121, no. 1, pp. e44-e52, 2008.

[31] B. Xiea, F. D. Gillilanda, Y. Lia, and H. R. H. Rockettb, "Effects of ethnicity, family income, and education on dietary intake among adolescents," Preventive Medicine, vol. 36, no. 1, pp. 3040, 2003.

[32] J. F. Guthrie, B. Lin, and E. Frazao, "Role of food prepared away from home in the American diet, 1977-78 versus 1994-96: changes and consequences," Journal of Nutrition Education and Behavior, vol. 34, no. 3, pp. 140-150, 2002.

[33] I. Colić-Barić, R. Kajfež, Z. Šatalić, and S. Cvjetić, "Comparison of dietary habits in the urban and rural Croatian schoolchildren," European Journal of Nutrition, vol. 43, no. 3, pp. 169-174, 2004.

[34] C. G. Russell and A. Worsley, "Do children's food preferences align with dietary recommendations?" Public Health Nutrition, vol. 10, no. 11, pp. 1223-1233, 2007.

[35] M. Story and D. Neumark-Sztainer, "A perspective on family meals: do they matter?" Nutrition Today, vol. 40, no. 6, pp. 261266, 2005.
[36] N. I. Larson, D. Neumark-Sztainer, P. J. Hannan, and M. Story, "Family meals during adolescence are associated with higher diet quality and healthful meal patterns during young adulthood," Journal of the American Dietetic Association, vol. 107, no. 9, pp. 1502-1510, 2007.

[37] D. Neumark-Sztainer, P. J. Hannan, M. Story, J. Croll, and C. Perry, "Family meal patterns: associations with sociodemographic characteristics and improved dietary intake among adolescents," Journal of the American Dietetic Association, vol. 103, no. 3, pp. 317-322, 2003.

[38] M. W. Gillman, S. L. Rifas-Shiman, A. L. Frazier et al., "Family dinner and diet quality among older children and adolescents," Archives of Family Medicine, vol. 9, no. 3, pp. 235-240, 2000.

[39] T. M. Videon and C. K. Manning, "Influences on adolescent eating patterns: the importance of family meals," Journal of Adolescent Health, vol. 32, no. 5, pp. 365-373, 2003.

[40] E. Taverns, S. Rifas-Shiman, C. Berkey et al., "Family dinner and adolescent overweight," Obesity Research, vol. 13, no. 5, pp. 900906, 2005.

[41] European Food Information Council (EUFIC), "Is eating between meals good for our health?" http://www.eufic.org/article/en/page/RARCHIVE/expid/review-eating-between-meals -health/.

[42] T. P. Pedersen, C. Meilstrup, B. E. Holstein, and M. Rasmussen, "Fruit and vegetable intake is associated with frequency of breakfast, lunch and evening meal: Cross-sectional study of 11-, 13-, and 15-year-olds," International Journal of Behavioral Nutrition and Physical Activity, vol. 9, article 9, 2012.

[43] G. Lazzeri, A. Pammolli, E. Azzolini et al., "Association between fruits and vegetables intake and frequency of breakfast and snacks consumption: a cross-sectional study," Nutrition Journal, vol. 12, no. 1, article 123, 2013. 


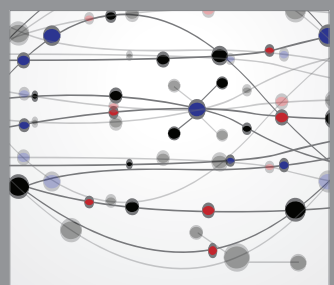

The Scientific World Journal
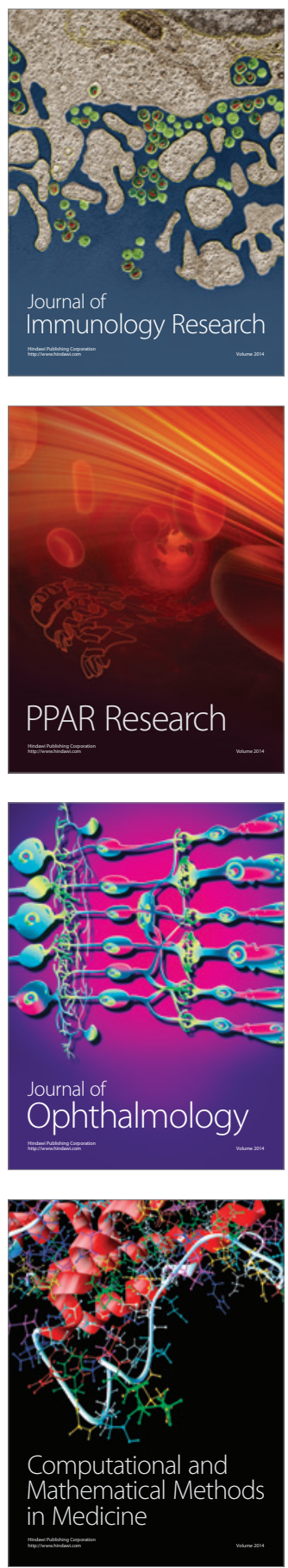

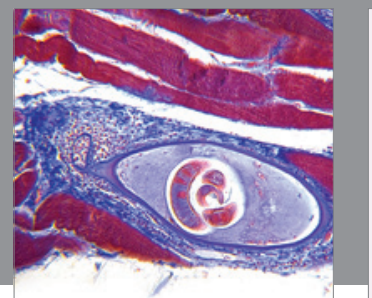

Gastroenterology

Research and Practice
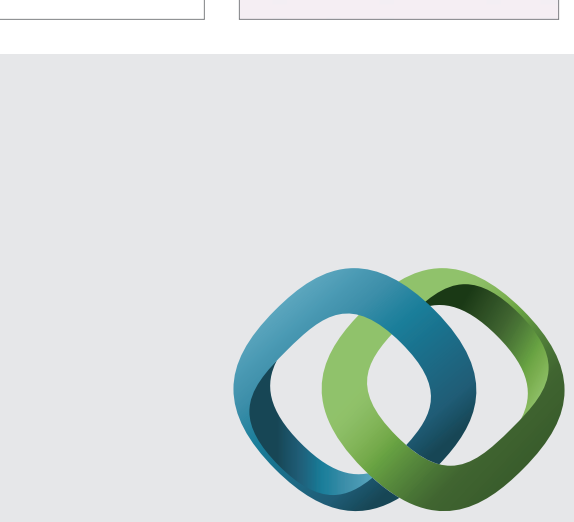

\section{Hindawi}

Submit your manuscripts at

http://www.hindawi.com
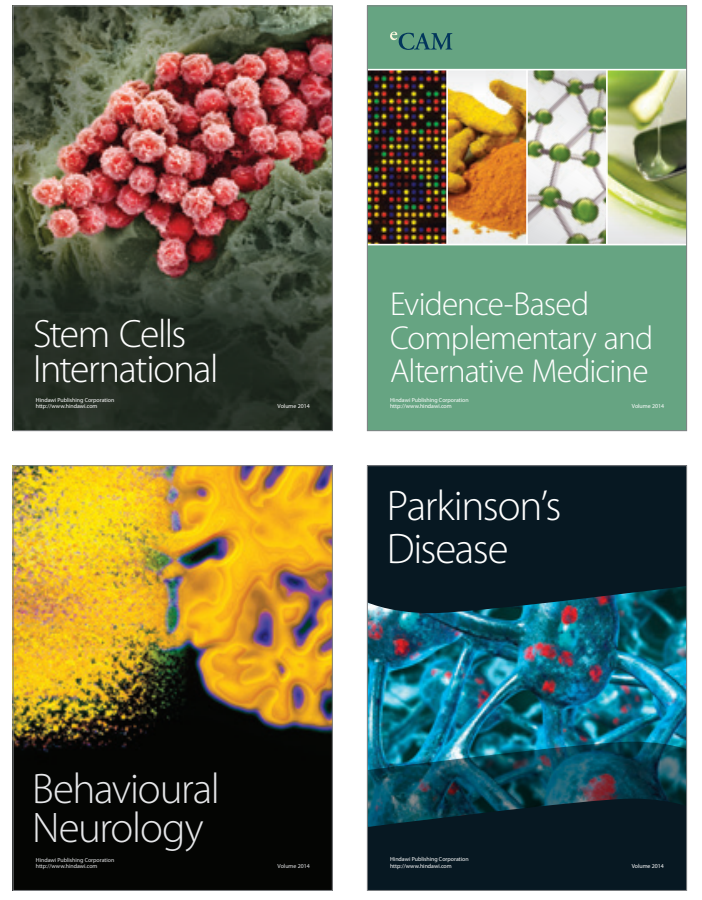
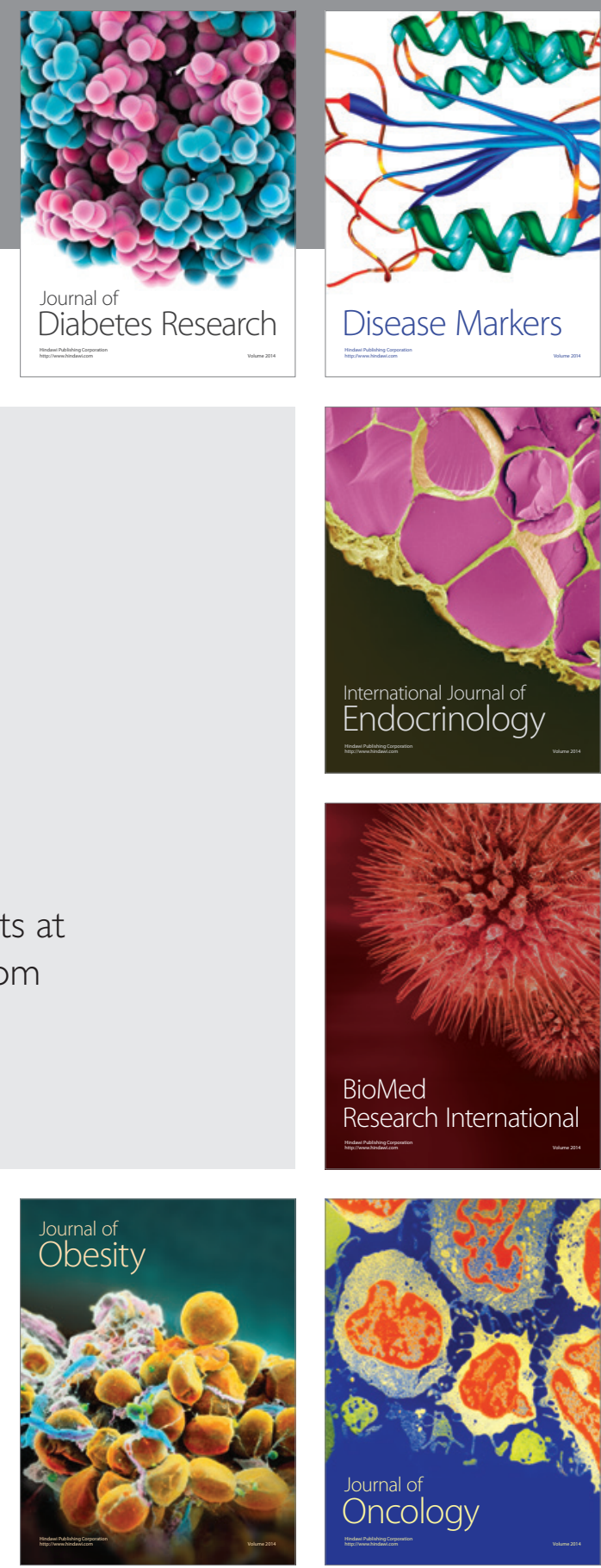

Disease Markers
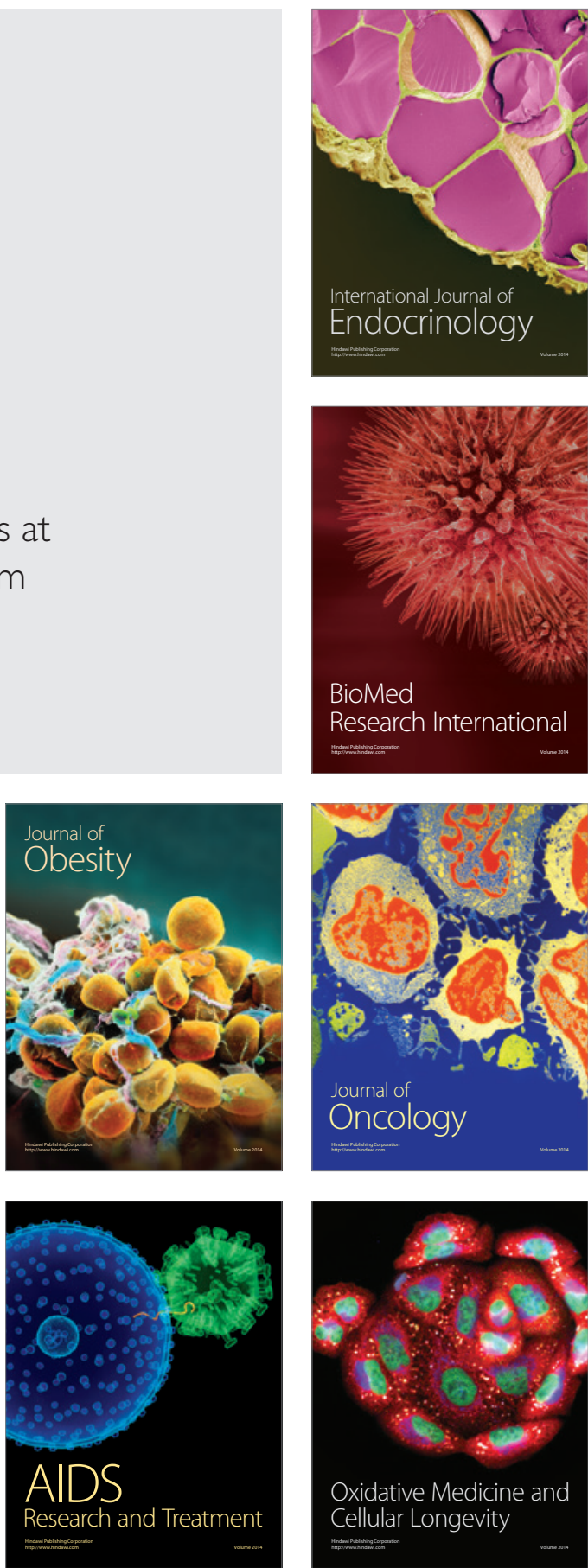